\title{
https://doi.org/10.46813/2020-130-150 \\ EFFECT OF ELECTRON EMISSION PROCESSES ON MACROPARTICLE CHARGING IN PLASMA SYSTEMS WITH ELECTRON BEAM
}

\author{
E.V. Romashchenko, I.O. Girka, A.A. Bizyukov, A.D. Chibisov \\ V.N. Karazin Kharkiv National University, Kharkiv, Ukraine \\ E-mail: ev.romashchenko@gmail.com
}

The effect of different electron emission processes on macropraticle (MP) charging in a plasma at the presence of electron beam is investigated. A complete model of the MP charging in the beam-plasma systems, which includes possible electron emission processes from the MP surface, such as secondary electron emission, the thermionic electron emission, the field electron emission and thermal-field electron emission, is presented.

PACS: 52.40.Hf

\section{INTRODUCTION}

Charging of a MP in beam-plasma systems is one of the basic problems in studies of interaction between the $\mathrm{MP}$ and the plasma. In the presence of electron beam there are several electron emission processes from the MP surface. First, the electron beam directly causes secondary electron-electron emission from the MP surface. The thermionic and field electron emissions are consequences of the MP bombardment by the electron beam due to the increasing of temperature and absolute value of negative potential of the MP, respectively. MP has a negative potential in the "usual" two-component low-temperature plasma due to higher mobility of electrons. The MP charging due to electron beam impact and MP recharging due to electron emission are competitive processes. Moreover, under certain conditions, effect of electron emission can even be more pronounced. As a result, MP can become positively charged.

In previous studies, MP charging in the electronbeam systems with account for the secondary electron emission has been investigated in the framework of the orbit motion limited (OML) approach [1] and on the basis of the discrete charging model [2]. The influence of field electron emission and secondary electron emission on MP potential has been studied in [3]. The effect of thermionic electron emission and secondary electron emission on MP potential has been investigated in [4].

In the present work, the studies of MP charging are developed. A complete model of the MP charging, which includes a possible electron emission processes from the MP surface in the presence of electron beam in the plasma, is presented. Obtained results are of importance for better understanding of the MP charging mechanisms in the beam-plasma systems.

\section{MP FLOATING POTENTIAL WITH ACCOUNT FOR EMISSION PROCESSES}

The steady-state potential $\varphi$, to which a MP is charged, is determined from the balance of particle fluxes which are collected by the MP surface and emitted from it:

$$
I_{i}(\varphi)+I_{e}(\varphi)+I_{b}(\varphi)+I_{e-e}(\varphi)+I_{e, T E}(\varphi)=0 .
$$

Here, $I_{i}$ is the ion current, $I_{e}$ is the current of plasma electrons , $I_{b}$ is the current of electron beam, $I_{e-e}$ is the current of secondary electrons emitted from the MP surface due to bombardment of electron beam, and $I_{e, T E}$ is the current of relevant electron emission (thermionic electron emission, field electron emission, thermal-field electron emission).

The currents $I_{i}, I_{e}$, and $I_{b}$ to the MP surface are calculated by using the OML theory [5]. The OML approach is applicable for MP radius $a$ much less than the Debye length $\lambda_{D}=\left(\varepsilon_{0} T_{e} / n_{0} e^{2}\right)^{1 / 2}: a<<\lambda_{D}$. In the case of negatively charged MP

$$
\begin{gathered}
I_{e}=\sqrt{8 \pi} a^{2} e n_{e} v_{T e} \exp \left(\frac{e \varphi}{k_{B} T_{e}}\right), \\
I_{i}=\sqrt{8 \pi} a^{2} e n_{i} v_{T i}\left(1-\frac{e \varphi}{k_{B} T_{i}}\right), \\
I_{b}=\pi a^{2} e n_{b} u_{e}\left(1-\frac{e \varphi}{\varepsilon_{e}}\right) .
\end{gathered}
$$

In the case of positively charged MP

$$
\begin{aligned}
& I_{e}=\sqrt{8 \pi} a^{2} e n_{e} v_{T e}\left(1+\frac{e \varphi}{k_{B} T_{e}}\right), \\
& I_{i}=\sqrt{8 \pi} a^{2} e n_{i} v_{T i} \exp \left(-\frac{e \varphi}{k_{B} T_{i}}\right), \\
& I_{b}=\pi a^{2} e n_{b} u_{e}\left(1+\frac{e \varphi}{\varepsilon_{e}}\right) .
\end{aligned}
$$

In (2)-(7) $n_{e}, n_{i}$, and $n_{b}$ are the particle density of plasma electrons, plasma ions and beam electrons, respectively; $T_{e}\left(T_{i}\right)$ is the electron (ion) temperature, $v_{T e}=\left(k_{B} T_{e} / m_{e}\right)^{1 / 2}\left(v_{T i}=\left(k_{B} T_{i} / m_{i}\right)^{1 / 2}\right)$ is the electron (ion) thermal velocity, $u_{e}$ is the velocity of beam electrons, $\varepsilon_{e}$ is the energy of beam electrons.

The secondary electron current $I_{e-e}$ caused by electron impact is [6]

$$
I_{e-e}=\delta I_{b}, \quad \varphi<0 .
$$

The secondary electron yield $\delta$ is described by Sterng-lass's universal curve [6]

$$
\delta=7.4 \delta_{m} \frac{\varepsilon_{e}}{\varepsilon_{m}} \exp \left(-2 \sqrt{\frac{\varepsilon_{e}-e \varphi}{\varepsilon_{m}}}\right),
$$


where $\varepsilon_{e m}$ is the energy for which the secondary yield $\delta_{m}$ is maximum.

In the case of positively charged MP, the vast majority of the secondary electrons returns to the MP surface and only the most energetic ones leave the surface. Thus, secondary electron current $I_{e-e}$ is given by:

$$
I_{e-e}=\delta I_{b} \exp \left(-\frac{e \varphi}{k_{B} T_{s}}\right)\left(1+\frac{e \varphi}{k_{B} T_{s}}\right), \varphi>0,
$$

where $T_{s}$ is the thermal temperature of emitted secondary electrons, which is quite small $(1 . .5 \mathrm{eV})$.

The secondary electron emission results in the sufficient increasing of absolute value of MP negative potential in the energy range of beam electrons, within which the secondary electron yield $\delta>1$. Moreover, in the case of the equality of plasma and electron beam densities, the MP floating potential can even become positive [1].

Another important emission process is the thermionic electron emission. The current density of thermionic electron emission is given by Richardson-Dushman equation [7]:

$$
j_{e, T E}=j_{e, R-D}=A_{P} T_{m p}^{2} \exp \left(-\frac{e \Phi}{k_{B} T_{m p}}\right),
$$

where $T_{m p}$ is the MP temperature, $e \Phi$ is the work function, $A_{R}$ is the Richardson constant. For most metals $A_{P}=(4 \ldots 7) \cdot 10^{5} \mathrm{~A} /\left(\mathrm{m}^{2} \cdot \mathrm{K}^{2}\right)[8]$.

The thermionic electron emission occurs if MP is heated to a temperature above some threshold. One can find this critical temperature by equating the plasma electron current density and current density of thermionic electron emission

$$
j_{e}=j_{e, T}
$$

where current density of electrons is expressed as:

$$
j_{e}=e n_{0}\left\langle v_{e}\right\rangle / 4 \text {. }
$$

Here, $n_{0}$ is the plasma particle density, $v_{T e}=\left(k_{B} T_{e}\right.$ $\left(m_{e}\right)^{1 / 2}$ is the average thermal velocity of electrons.

MP critical temperature $T_{c r}(K)$

\begin{tabular}{|l|l|c|c|}
\hline & \multirow{2}{*}{$\begin{array}{c}e \Phi, \\
\mathrm{eV}\end{array}$} & \multicolumn{2}{|c|}{$T_{e}=10 \mathrm{eV}$} \\
\cline { 3 - 4 } & $n_{0}=10^{15} \mathrm{~m}^{-3}$ & $n_{0}=10^{16} \mathrm{~m}^{-3}$ \\
\hline $\mathrm{Al}$ & 4.2 & 2023 & 2218 \\
\hline $\mathrm{Ti}$ & 4.3 & 2068 & 2267 \\
\hline $\mathrm{eu}, \mathrm{W}$ & 4.5 & 2156 & 2363 \\
\hline
\end{tabular}

The results of calculations of critical temperature $T_{c r}$ for MP with different work function material such as aluminium, titanium, copper and tungsten in the plasma with electron temperature $T_{e}=10 \mathrm{eV}$ and plasma density $n_{0}=10^{15} \ldots 10^{16} \mathrm{~m}^{-3}$ are presented in the Table. For all the materials, except tungsten, the critical temperature is higher than the boiling temperature. The value of critical temperature of MP turns out to be higher in the plasma with density $10^{16} \mathrm{~m}^{-3}$ than that in the plasma with the smaller density $10^{15} \mathrm{~m}^{-3}$.

In the case of negatively charged MP, the repulsive potential accelerates thermionic electrons from the MP surface. The electric field causes the increase in the work function due to the electrostatic barrier. Richard-
son-Dushman equation with Schottky correction for the work function is

$$
j_{e, T E}=j_{e, R-S h}=A_{P} T_{m p}^{2} \exp \left(-\frac{e \Phi-b \sqrt{E}}{k_{B} T_{m p}}\right),
$$

where $E$ is the electric field. This equation is also called as Richardson-Schottky equation.

The electric field on the MP surface is related to the electric potential by

$$
E=\varphi / a
$$

and Schottky correction can be rewritten as

$$
b \sqrt{E=}=\Delta \Phi=\sqrt{\frac{e^{3} \varphi}{4 \pi \varepsilon_{0} a}} .
$$

When the MP is positively charged, the electrons have to overcome the floating potential and the surface barrier. In this case, the current density of the thermionic emission is given by [9]

$$
j_{e, T E}=A_{P} T_{M Y}^{2}\left(1+\frac{e \varphi}{k_{B} T_{m p}}\right) \exp \left(-\frac{e \Phi+e \Delta \Phi}{k_{B} T_{m p}}\right) .
$$

In the case of very strong electric field, when $e \Delta \Phi>e \Phi$, there is the field electron emission from MP surface. In this case the emission current density should be calculated according to Fowler-Nordheim formula [7]:

$$
j_{e, \Phi-H}=\frac{e^{2} E^{2}}{8 \pi h \Phi t^{2}(y)} \exp \left(-\frac{8 \pi \sqrt{2 m_{e}(e \Phi)^{3}}}{3 e h E} v(y)\right)
$$

with

$$
y \equiv \sqrt{\frac{e^{3} E}{4 \pi \varepsilon_{0}}} \frac{1}{e \Phi} .
$$

In (18), $t(y)$ and $v(y)$ are the elliptical functions [7].

Field electron emission from a MP occurs when its surface electric field is about $2 \cdot 10^{7} \mathrm{~V} / \mathrm{cm}$. In the following, the plasma conditions and MP size, under which MP has such electric field on its surface, are evaluated. The field emission from MP surface is absent in the case of low-temperature plasma, which consists of electrons and ions. For example, in nitrogen plasma with $T_{e} / T_{i}=10$ normalized potential $z=-e \varphi / k_{B} T_{e}=10$ [8]. The corresponding electric field on the surface of the MP with radius $1 \mu \mathrm{m}$ equals $3 \cdot 10^{5}$ and $3 \cdot 10^{6} \mathrm{~V} / \mathrm{cm}$ for MP with radius $0.1 \mu \mathrm{m}$. However, the field emission from MP surface is possible in the case of plasma with electron beam. The MP can acquire the high negative charge due to bombardment of electron beam. The floating potential of MP reaches $-200 \mathrm{~V}$ for beam electron energy of the order of a few $\mathrm{keV}$ [1]. If electric potential of MP with radius $0.1 \mu \mathrm{m}$ equals $-200 \mathrm{~V}$, the corresponding electric field on its surface is $2 \cdot 10^{7} \mathrm{~V} / \mathrm{cm}$. Thus, the field emission becomes important for MP with radius of about $0.1 \mu \mathrm{m}$.

We have emission formulas (14) and (18) for two cases: thermionic electron emission with taking into account the Schottky effect, and field electron emission, respectively. The relevant temperature and electric field ranges are determined by [10]:

$$
e \Phi-\sqrt{\frac{e^{3} E}{4 \pi \varepsilon_{0}}}>\frac{\hbar}{\pi \sqrt{m_{e} e}}\left(\frac{e^{3} E}{4 \pi \varepsilon_{0}}\right)^{3 / 4}+\frac{k_{\mathrm{B}} T_{m p}}{1-c k_{B} T_{m p}},
$$




$$
1-c k_{B} T_{m p}>\sqrt{2 f} k_{B} T_{m p}
$$

Here,

$$
c \equiv 2 \sqrt{\frac{2 m_{e}}{\hbar^{2}}} \frac{\sqrt{e \Phi}}{e E} t(y),
$$

$\hbar$ is the Plank constant, and

$$
f \equiv \frac{1}{2} \sqrt{\frac{2 m_{e}}{\hbar^{2}}} \frac{v(y)}{e E \sqrt{e \Phi}}\left(1-\frac{e E}{4 \pi \varepsilon_{0} \Phi^{2}}\right)^{-1} .
$$

The electric field-temperature curves calculated from (20) and (21) divide the diagram in the Fig. 1 into three regions: first one marked as TE, which corresponds to the thermionic electron emission; second one marked as FE, which corresponds to the field electron emission, and a large region TFE between them. Both temperature and electric field are high in the latter. Such a case is possible in the vacuum arc discharge. Electron emission in TFE range of temperatures and electric fields belongs to so-called thermal-field emission. The current density of thermal-field emission is given by Murphy-Good formula [7]:

$$
j_{e, M-G}=\frac{e m_{e}\left(k_{B} T_{m p}\right)^{2}}{2 \pi^{2} \hbar^{3}}\left(\frac{\pi h_{0}}{\sin \pi h_{0}}\right) \exp \left(-\frac{e \Phi-b \sqrt{E}}{k_{B} T_{m p}}\right),
$$

were

$$
h_{0} \equiv\left(\frac{E \hbar^{4}}{m_{e}^{2} e^{5}}\right)^{1 / 4} \frac{b \sqrt{E}}{\pi k_{B} T_{m p}} .
$$

Murphy-Good theory is the more general approach. The formula (24) in the limiting cases transforms to the Richardson-Schottky thermionic emission formula (14) and Fowler-Nordheim field emission formula (18):

$$
j_{e, T E}=\left\{\begin{array}{l}
j_{e, R-S h}, \pi h_{0}<<1 ; \\
j_{e, F-N}, e \Phi<e \Delta \Phi .
\end{array}\right.
$$

Besides, the thermo-field (thermionic) emission current $I_{e, T E}$ from the MP surface is limited by the space charge. The maximum current is determined by Langmuir-Blodgett formula [11]:

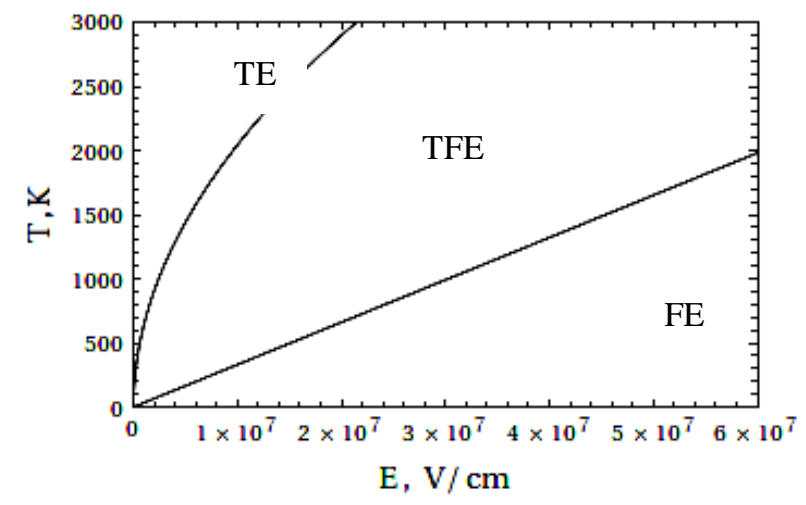

Fig. 1. Thermionic emission (TE), field emission (FE) and thermal-field emission (TFE) regions of

temperature and electric field for $4.5 \mathrm{eV}$ work function

$$
I_{3 / 2}=\frac{\sqrt{2 \varepsilon_{0}}}{9 \pi} \sqrt{\frac{e}{m_{e}}} \frac{U^{3 / 2}}{\alpha^{2}},
$$

where $\alpha$ is the tabulated function [11].

Thus, the thermal-field (thermionic) emission current $I_{e, T E}$ from the MP surface is determined by the following conditions:

$$
I_{e, T E}=\left\{\begin{array}{l}
I_{e}^{3 / 2}, I_{e, T E}(\varphi)>I_{e}^{3 / 2}(\varphi) \\
I_{e, T E}, I_{e, T E}(\varphi)<I_{e}^{3 / 2}(\varphi) .
\end{array}\right.
$$

One can conclude that the solution of current balance equation (1) requires careful choice of the appropriate expression for emission current. At the same time, one must keep in mind that electron emission is a limiting process.

\section{RESULTS AND DISCUSSION}

The current balance equation (1) is numerically solved in the two limiting cases: for MP with high temperature and weak surface electric field, and for MP with low temperature and strong surface electric field. The numerical calculations are carried out for a collisionless nitrogen plasma with the density of $n_{0}=10^{16} \mathrm{~m}^{-3}$, electron temperature of $T_{e}=10 \mathrm{eV}$, ion temperature of $T_{i}=1 \mathrm{eV}$, electron beam density of $n_{0}=10^{15} \mathrm{~m}^{-3}$, and electron beam energies of $\varepsilon_{e}=0.01 \ldots 5 \mathrm{keV}$.

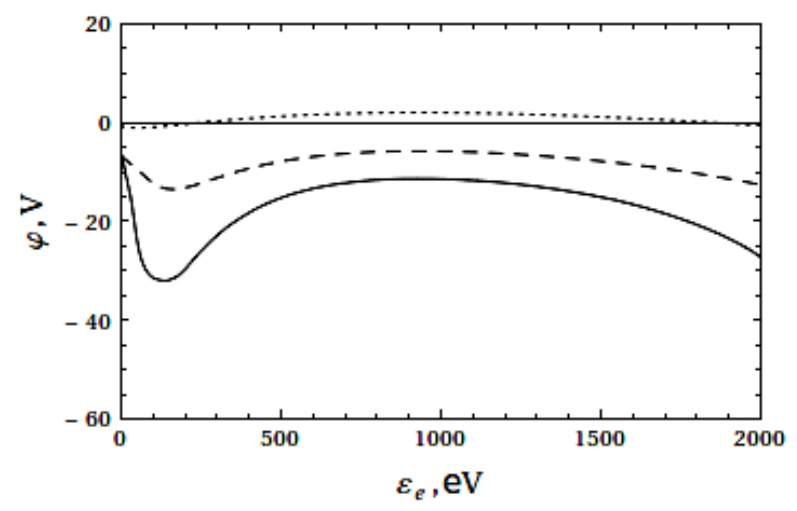

Fig. 2. The floating potential of MP with radius $1 \mu \mathrm{m}$ versus the electron beam energy for different $M P$ temperatures: "cold" MP ( solid line), $T_{m p}=2363 \mathrm{~K}$ (dashed line); $T_{m p}=2500 \mathrm{~K}$ (dotted line)

To begin with, the tungsten MP with radius $a=1 \mu \mathrm{m}$ is considered at fixed temperatures: $T_{m p}=2363 \mathrm{~K}$ (critical temperature) and $T_{m p}=2500 \mathrm{~K}$ in the energy range of beam electrons $\varepsilon_{e}=0.01 \ldots 5 \mathrm{keV}$. This case corresponds to the thermionic electron emission. The emission current is calculated according to the Richardson-Dushman equation (3) with taking into account the Schottky effect. If MP is positively charged, emission current density is calculated according to (9). The floating potential of MP as a function of the electron beam energy is shown in Fig. 2. The potential of "cold" MP turns out to be negative in the whole energy range of beam electrons. The secondary electron emission cannot lead to positive potential in the plasma with density larger than density of electron beam. At the temperature $T_{m p}=2363 \mathrm{~K}$, the MP potential increases, but it remains negative. At the higher temperature $T_{m p}=2500 \mathrm{~K}$, the MP potential becomes positive. 
The other example is shown in Fig. 3. The tungsten MP with radius $0.1 \mu \mathrm{m}$ yields a high electric field at electron beam energy more than $2 \mathrm{keV}$. The Fig. 3 shows the comparison of MP potential without taking into account the field emission, and with it. One can see that in the first case, the MP potential $\varphi=-400 \mathrm{~V}$ for the electron beam energy $\varepsilon_{e}=4 \mathrm{keV}$, and in the second case, $\varphi=-300 \mathrm{~V}$. Thus, the field electron emission sufficiently decreases the absolute value of negative MP potential.

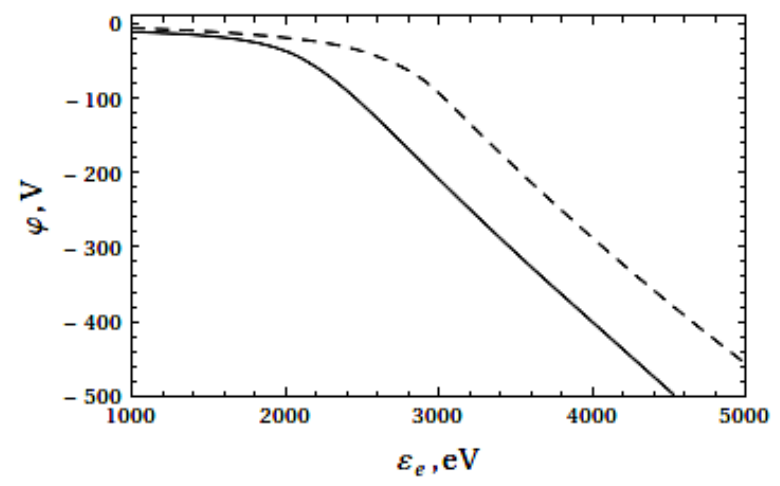

Fig. 3. The floating potential of MP with radius $0.1 \mu \mathrm{m}$ versus the electron beam energy. MP potential is calculated without taking into account the field emission (solid line). MP potential is calculated with taking into account the field emission (dashed line)

\section{CONCLUSIONS}

The present paper describes the mechanisms of different kind of electron emission from MP in plasma system in the presence of electron beam. Both field electron emission and thermionic electron emissions result in the increasing of absolute value of MP negative potential. However, the field electron emission does not change the sign of the MP potential. This is explained by the difference of the energy range of beam electrons, at which the thermionic and field electron emissions take place.

\section{REFERENCES}

1. A.A. Bizyukov, E.V. Romashchenko, K.N. Sereda, and A.D. Chibisov. Electric potential of a macroparticle in beam-plasma systems // Plasma Physics Reports. 2009, v. 35, № 6, p. 499-501.

2. A.A. Bizyukov, E.V. Romashchenko, K.N. Sereda, and S.N. Abolmasov. Particle charging in beam-plasma systems // Problems of Atomic Science and Technology. Series «Plasma Physics» (19). 2013, № 1, p. 183-185.

3. A.A. Bizyukov, K.N. Sereda, and A.D. Chibisov. Charging processes of metal macroparticles in the lowtemperature plasma at presence of high-energy electron beam // Problems of Atomic Science and Technology. Series «Plasma Physics» (17). 2011, № 1, p. 107-109.

4. A.A. Bizyukov, E.V. Romashchenko, K.N. Sereda, A.D. Chibisov, A.V. Nasarov. Emission characteristics and potential of macroparticle in beam-plasma discharge // Problems of Atomic Science and Technology. Series «Plasma Physics» (14). 2008, № 6, p. 162-164.

5. H.M. Mott-Smith, I. Langmuir. The theory of collectors in gaseous discharges // Phys. Rev. 1926, v. 28, p. 727-763.

6. E.J. Sternglass. The theory of secondary electron emission. Westinghouse Res. Lab. Sci. Pap, 1972.

7. E.L. Murphy, R.H. Good. Thermionic emission, field emission and the transition region // Phys. Rev. 1956, v. 102, p. 1464-1473.

8. A. Anders. Cathodic Arcs: From Fractal Spots to Energetic Condensation. New York: "Springer", 2008.

9. G.L. Delzanno, G. Lapenta, M. Rosenberg. Attractive potential around a thermionically emitting microparticle // Phys. Rev. Letters. 2004, v. 92, № 3, p. 035002.

10. A. Modinas. Field, Thermionic and Secondary Electron Emission Spectroscopy. New York: "SpringerScience+Business Media, LLC”, 1984, p. 372.

11. I. Langmuir, K.B. Blodgett. Current limited by space charge between concentric spheres // Phys. Rev. 1924, v. 24, № 1, p. 49-59.

Article received 03.10.2020

\title{
ВЛИЯНИЕ ПРОЦЕССОВ ЕЛЕКТРОННОЙ ЕМИССИИ НА ЗАРЯДКУ МАКРОЧАСТИЦЫ В ПЛАЗМЕННЫХ СИСТЕМАХ С ЭЛЕКТРОННЫМ ПУЧКОМ
}

\author{
Е.В. Ромащенко, И.А. Гирка, А.А. Бизюков, А.Д. Чибисов
}

Исследовано влияние различных процессов электронной эмиссии на зарядку макрочастицы (МЧ) в плазме в присутствии электронного пучка. Представлена полная модель зарядки МЧ в пучково-плазменных системах, которая включает в себя возможные процессы электронной эмиссии с поверхности МЧ, такие как вторичная электрон-электронная эмиссия, термоэлектронная, автоэлектронная, термоавтоэлектронная эмиссии.

\section{ВПЛИВ ПРОЦЕСІВ ЕЛЕКТРОННОЇ ЕМІСІЇ НА ЗАРЯДЖЕННЯ МАКРОЧАСТИНКИ У ПЛАЗМОВИХ СИСТЕМАХ 3 ЕЛЕКТРОННИМ ПУЧКОМ}

\section{О.В. Ромащенко, І.О. Гірка, О.А. Бізюков, О.Д. Чібісов}

Досліджено вплив різних процесів електронної емісії на зарядження макрочастинки (МЧ) у плазмі у присутності електронного пучка. Подано повну модель зарядження МЧ у пучково-плазмових системах, до складу якої входять можливі процеси електронної емісії з поверхні МЧ, такі як вторинна електронелектронна емісія, термоелектронна, автоелектронна та термоавтоелектронна емісії. 